\title{
La colegiatura de la abogacía y la violencia institucional ${ }^{*}$
}

\author{
Recibido: 24 de julio de 2018 • Aprobado: 5 de diciembre de 2018 \\ https://doi.org/10.22395/ojum.v18n37a6
}

Hugo Omar Seleme*

\section{RESUMEN}

El presente trabajo tiene por objetivo mostrar que existen tres teorías políticas que pueden utilizarse para justificar la colegiatura profesional de los abogados: el corporativismo, el pluralismo y el republicanismo. La teoría política que se adopte determinará el modo de concebir las funciones que el colegio de abogados ejerce en relación con el Estado. El trabajo específicamente se concentra en mostrar que la colegiatura funciona como un límite frente a la violencia institucional, cuando el paradigma adoptado es uno de tipo republicano.

Palabras clave: pluralismo; republicanismo; corporativismo; colegiación de abogados.

Artículo de reflexión, realizado con el apoyo económico de un proyecto de investigación plurianual (Argentina) 2016-2018 radicado en el Centro de Investigaciones Jurídicas y Sociales de la Facultad de Derecho de la Universidad Nacional de Córdoba, Argentina.

** Abogado, Universidad Nacional de Córdoba, Argentina, Profesor en Filosofía y Ciencias de la Educación, Instituto Católico del Profesorado de Córdoba (ICPC), Argentina, doctor en Derecho y Ciencias Sociales, Universidad Nacional de Córdoba, Argentina, investigador del Conicet, Argentina, catedrático de Ética y profesor de Filosofía del Derecho, Facultad de Derecho, Universidad Nacional de Córdoba, Argentina, director del Programa de Ética y Teoría Política y de la Maestría en Derecho y Argumentación, Facultad de Derecho, Universidad Nacional de Córdoba, Argentina. Correo electrónico: hugoseleme@conicet. gov.ar. Orcid: https://orcid.org/0000-0003-0658-0512 


\section{Fellowship of Law and Violence}

\section{ABSTRACT}

This article's main goal is displaying the existence of three political theories that might be used for justifying the professional fellowship of lawyers; the corporatism, the pluralism, the republicanism. The political theory adopted will determine the conception of the functions that the lawyer's fellowships perform in its relationship with the State. This work specifically focuses on showing that the fellowship functions as a limit for institutional violence when the adopted paradigm is a republican one.

Keywords: pluralism; republicanism; corporatism; lawyers fellowship.

\section{A escola de advogados e a violência institucional}

\section{RESUMO}

Este trabalho tem o objetivo de mostrar que existem três teorias políticas que podem ser utilizadas para justificar a escola de advogados profissional: o corporativismo, o pluralismo e o republicanismo. A teoria política que se adapte determinará o modo de conceber as funções que a escola de advogados exerce com relação ao Estado. Em específico, o trabalho se concentra em mostrar que o colegiado funciona como um limite ante a violência institucional, quando o paradigma adotado é de tipo republicano.

Palavras-chave: pluralismo; republicanismo; corporativismo; escola de advogados. 


\section{INTRODUCCIÓN}

Existen tres maneras diferentes de concebir el rol de los colegios de abogados según cuál sea el tipo de teoría política que se adopte para justificar su existencia. Esto no es de extrañar dado que las pautas legales hunden sus raíces en la teoría política. Específicamente en lo que respecta a la regulación del ejercicio de la profesión de abogado y la exigencia de colegiatura, es posible identificar tres teorías políticas diversas que pueden darle sustento: el corporativismo, el pluralismo y el republicanismo.

Que una misma institución -la colegiatura- pueda ser justificada a partir de teorías políticas tan diversas trae aparejados tanto problemas teóricos como prácticos. Los primeros, tienen que ver con identificar cuál de estas concepciones políticas ha sido la que ha tenido influencia sobre los particulares ordenamientos jurídicos que regulan la profesión de abogado. El problema se agrava cuando se advierte que, al momento de regular la colegiatura en un determinado sistema jurídico-político, es posible que hayan incidido consideraciones provenientes de diferentes concepciones políticas, muchas veces en pugna e incompatibles entre sí. De lo que se trata aquí es de examinar si es posible armonizar estos enfoques, aparentemente en tensión, que se encuentran en la base política que sirvió para justificar la colegiatura.

Los problemas prácticos, por otro lado, son de dos tipos. Uno, se refiere a la manera en que debe interpretarse el rol de los colegios de abogados en las diferentes jurisdicciones. Por supuesto, esto tiene vinculación con el problema teórico referido a su justificación, pero es un problema diferente que merece análisis separado. El otro, tiene que ver con el diferente modo de concebir el rol de los colegios de abogados según que se los articule alrededor de una teoría política u otra.

En el presente trabajo me ocupo, en primer lugar, del problema teórico, para luego precisar la incidencia que los diferentes modos de justificación de la colegiatura tienen sobre un problema concreto. Específicamente, me interesa mostrar la diferente función que deben tener los colegios de abogados, según cuál sea la teoría política que los informe, frente al problema de la violencia institucional. De manera que el primer tipo de problema práctico, referido al estudio de las disposiciones legales que regulan la colegiatura y el ejercicio de la profesión en las diferentes jurisdicciones locales, no será objeto de indagación.

Elegir el problema de la violencia institucional como caso testigo para analizar el diferente rol de los colegios de abogados, según posean una impronta corporativista, pluralista o republicana, no es algo casual. La violencia institucional, entendida como aquella ejercida de manera ilegítima por los agentes o funcionarios gubernamentales ${ }^{1}$

Existe una idea más amplia de violencia institucional que amplía el espectro de agentes que pueden ejercitarla y ámbitos donde puede desarrollarse (Barak, 2003, pp. 77-112). 
-el caso paradigmático es la ejercida por las fuerzas de seguridad cuando extralimitan sus funciones- es una de las principales amenazas al efectivo goce de los derechos humanos por amplias franjas de la población en América Latina. Esto se debe, en parte, a un pasado poblado por gobiernos dictatoriales que contribuyeron a forjar prácticas y cosmovisiones que, mucho después de haber sido desalojados del poder, siguen estando presentes en las instituciones públicas. Las prácticas policiales de detener a ciudadanos sin ningún otro motivo que la averiguación de antecedentes, por encontrarlos en una actitud sospechosa, o simplemente por su aspecto físico o modo de vestir, son un resabio de gobiernos dictatoriales que concebían a los ciudadanos como potenciales delincuentes o amenazas al orden público, y no como sujetos de derechos.

Los efectos de la violencia institucional corporizada en un entramado institucional que distribuye las libertades, oportunidades y recursos materiales de un modo arbitrario -condenando a franjas de la población a vivir en la indigencia- son mantenidos ocultos y bajo control por la violencia institucional ejercida a través de las fuerzas de seguridad que impiden a las víctimas ser escuchadas o percibidas. Con la excusa de combatir la delincuencia han ganado terreno políticas de seguridad dirigidas a la ocupación y el control de las zonas marginales de los conglomerados urbanos. El resultado inmediato ha sido la aparición de guetos con paredes invisibles construidas con retenes policiales que filtran la población que puede trasladarse de la periferia al centro de nuestras ciudades ${ }^{2}$.

Es un lugar común concebir a la profesión de abogado como aquella orientada a garantizar el respeto de los derechos individuales, y si la violencia institucional es una de las principales amenazas que pesa sobre estos derechos, y la colegiación una de las características que ha adoptado el ejercicio profesional, es lógico preguntarse por cuál debería ser el rol de los colegios de abogados frente a ella. La manera en que las asociaciones profesionales de abogados se han posicionado frente a la violencia ejercitada desde el Estado ha variado aun dentro de una misma jurisdicción nacional. En Argentina, por ejemplo, mientras el Colegio de Abogados de la Ciudad de Buenos Aires se posicionó a favor del gobierno de facto de la Revolución libertadora que persiguió a militantes peronistas y pobló las cárceles con presos políticos, la Federación Argentina de Colegios de Abogados tuvo una posición contraria a la violencia institucional desatada durante el gobierno dictatorial del general Roberto Levingston. La Asociación de Abogados, en cambio, controlada por el grupo conducido por Carlos Fayt, futuro miembro de la Corte Suprema, guardó silencio frente a la desaparición de abogados

2 El caso de la ciudad que habito -Córdoba, Argentina- es paradigmático, aunque lamentablemente no es el único. Dos políticas públicas concretas han contribuido a crear allí estos guetos de paredes invisibles. La primera, ha sido la reubicación de personas carenciadas en denominados barrios ciudades ubicados en la periferia del trazado urbano.La segunda, ha consistido en una aplicación selectiva del derecho contravencional sobre las personas carenciadas evitando su circulación hacia el centro de la ciudad (Espoz, 2009; Bisig, 2014). 
que defendían a presos políticos ${ }^{3}$. En Colombia, por citar otro ejemplo, el Colegio de Abogados de Medellín sostuvo una actitud de resistencia frente a la dictadura de Rojas Pinilla, mientras otras asociaciones profesionales optaron por el silencio ${ }^{4}$.

\section{TRES TEORIAS POLIITICAS}

Diversas teorías políticas han incidido en el modo de entender las funciones de los colegios profesionales. Las ideas republicanas -centradas en el valor político de evitar la dominación- pluralistas -según las cuales la política es una competencia de diferentes grupos de interés en busca de la supremacía- y corporativistas - que conciben a la comunidad política como compuesta de diferentes grupos con intereses divergentes pero armónicos-, han estado presentes en la cultura pública de los países latinoamericanos desde sus orígenes. Las ideas corporativistas hunden sus raíces en el modo medieval de entender la política y permearon gran parte de las instituciones coloniales. Las republicanas y pluralistas, muchas veces enlazadas, ingresaron para fundar los reclamos de independencia de las nuevas naciones. Dada su ubicuidad estas ideas han influido en la manera en que diseñamos e interpretamos nuestras instituciones.

En lo que sigue, pretendo detenerme a mostrar las maneras diversas en que quedan configuradas las funciones de una institución en particular -los colegios profesionales de abogados- según que se adopte una u otra de estas teorías políticas.

\subsection{Corporativismo}

La visión corporativa de la sociedad puede rastrearse hasta antes del surgimiento del Estado moderno. Antes de que este reclamase el monopolio del poder para legislar y coaccionar, algunas organizaciones corporativas, como los gremios o la Iglesia católica, adquirieron poder para regular el accionar de sus miembros. Durante la Edad Media proliferaron las asociaciones profesionales dotadas de poder para organizar y controlar el ejercicio de ciertas actividades productivas 5 .

Fue la Iglesia católica la primera en articular, durante este período histórico, una visión corporativa de sociedad. Esta idea de sociedad quedó plasmada en el derecho canónico que reconocía un rol fundamental a corporaciones. Entre estas se encontraban las ordenes religiosas, los gremios o las universidades y colegios mayores. La

3 Esta actitud cómplice de la Asociación de Abogados provocó que un grupo de abogados disconformes fundaran la Asociación Gremial de Abogados (Celesia y Waisberg, 2016, pp. 45-46)

4 Agradezco a un árbitro anónimo el haberme facilitado esta referencia acerca de la actuación del Colegio de Abogados de Medellín.

5 Un análisis pormenorizado de la forma corporatista de organización estatal puede encontrarse en Cox y O'Sullivan (1988). 
sociedad era concebida como una especie de organismo compuesto por diferentes órganos -representados por las corporaciones- cada uno con una función y una regulación propia. El afianzamiento de esta idea corporativa de la sociedad dentro de la Iglesia católica sin duda se vio favorecido por el hecho de que la propia Iglesia se veía a sí misma de manera corporativa, como un organismo o como el cuerpo místico de Cristo.

El surgimiento del Estado moderno, con su pretensión de monopolizar el control del entramado social, y la organización de la producción a través del libre mercado, puso en retirada a la visión corporativista de sociedad medieval. Los gremios perdieron su poder para regular las actividades profesionales a manos del Estado, y el ejercicio de las profesiones en general se liberalizó pasando a ser regido por las leyes de la oferta y la demanda.

El primer intento de armonizar las antiguas ideas corporativistas con el Estado moderno provino, como era de prever, de la Iglesia católica. Lo realizó el papa León XIII en su encíclica Rerum Novarum del año 1891. Como una manera de evitar la lucha de clases, pregonada por toda Europa, el documento proponía el funcionamiento de asociaciones de trabajadores y empleadores. El conflicto social, de acuerdo con esta visión renovada de corporativismo, podía ser manejado por instituciones cuya representación estaba basada en la ocupación o profesión de sus miembros ${ }^{6}$. Organizar a los trabajadores y a los empleadores en asociaciones permitiría articular las demandas que cada sector tenía para hacer al otro, a la vez que permitiría que cada asociación disciplinase los reclamos de cada uno de sus miembros ${ }^{7}$. Esta adaptación de las ideas corporativas al nuevo escenario, caracterizado por la existencia de un Estado con monopolio legislativo y un clima de creciente protesta social que amenazaba a conducir inevitablemente a la lucha de clases, tuvo especial acogida en los países del sur de Europa donde el catolicismo era la religión mayoritaria. Esto explica, en parte, porqué el fascismo italiano de Benito Mussolini, el español de Francisco Franco, y el portugués de Antonio de Oliveira Salazar, adoptaron esta nueva versión de corporativismo a la hora de montar su crítica al sistema político democrático y liberal.

Por supuesto, el fascismo agregó a la visión corporativa de sociedad otros elementos virulentos como el autoritarismo político y el exacerbado nacionalismo. El corporativismo, con todo, ocupaba en su concepción política un lugar central. Este modo de concebir la sociedad le permitía a la vez distanciarse de sus dos enemigos

6 Como consecuencia de este enfoque adoptado por la Iglesia católica proliferaron en Francia las llamadas fábricas cristianas que intentaban llevar los principios corporativistas a la organización fabril. La experiencia más conocida fue la llevada adelante por León Harmel en Val-des-Bois (Coffey, 2003).

7 Sobre la evolución de las ideas políticas en el seno del catolicismo, y su deriva corporativista desde finales del siglo XIX, puede cotejarse Hanson (1987). 
declarados: el comunismo y el liberalismo. En lugar de individuos organizados en clases con intereses conflictivos -como proponía el comunismo- o de individuos atomizados persiguiendo solo su interés individual -como proponía el liberalismoel corporativismo proponía una sociedad donde los individuos se organizaban en asociaciones o gremios profesionales cuyos reclamos sectoriales eran articulados por la acción estatal con el objetivo de satisfacer el bien común, o el progreso de la nación.

Si se la purifica de sus ribetes autoritarios, esta nueva variante de corporativismo se caracteriza por establecer una relación de beneficio recíproco entre el Estado y las asociaciones o gremios profesionales. El Estado reconoce a las asociaciones de trabajadores, profesionales, empresarios, etc., el derecho para representar de manera legítima los intereses del grupo que nuclean. Estas adquieren así un grado de preeminencia para mediar los reclamos sociales, del que carecerían si no les fuese concedido por el Estado. Coincidente con el otorgamiento de esta representatividad, el Estado a la hora de diseñar políticas públicas consulta a las asociaciones tomándolas como el principal vehículo por el cual cada sector productivo o social hace oír su voz y promueve sus intereses. Adicionalmente, el Estado delega en las asociaciones la capacidad para dictar regulaciones, para determinar cuándo las reglamentaciones han sido transgredidas, y para imponer sanciones. Como contrapartida, las asociaciones se involucran en la tarea de garantizar que las políticas estatales acordadas sean efectivamente implementadas. Específicamente, cada asociación asume el compromiso de ser el brazo ejecutivo de las políticas estatales para el sector que representa. Según señala Chub, el Estado puede, de este modo, "build support for the enactment and implementation of its policies by granting privileged participation to a sectoral interest group sufficiently powerful to deliver the support of its benefiting constituency" (1983, p. 26).

Según si el Estado se involucra o no en el surgimiento de las corporaciones que representan a los diferentes sectores sociales y productivos, el corporativismo puede ser societal o estatal ${ }^{8}$. En el primer caso, el Estado corporativo se vale de asociaciones surgidas con independencia de su intervención. El surgimiento de las asociaciones no es inducido ni promovido por la intervención estatal. Este tipo de corporativismo ha sido característico de países como Suecia y Holanda. En el segundo, por el contrario, el Estado crea o incentiva el surgimiento de las corporaciones que actúan como órganos estatales auxiliares y, por ende, dependientes. Ejemplos de este tipo

8 Otra clasificación no tiene en cuenta el carácter, espontáneo o creado a través de la intervención estatal, de las asociaciones sino su tamaño. Para este enfoque existen tres variantes de corporativismo, a saber, el macrocorporativismo, donde el Estado interactúa con grandes asociaciones de obreros y empresarios; el mesocorporativismo que involucra a asociaciones más especializadas y el microcorporativismo donde la interacción se da con empresas y grupos de obreros en particular (Schmitter y Lehmbruch, 1985). 
de corporativismo pueden encontrarse en Portugal durante la época de Salazar, o en la Italia de Mussolini9.

\subsection{Pluralismo}

La versión de pluralismo político que tengo en mente hunde sus raíces en las ideas de uno de los padres fundadores de la Constitución estadounidense. James Madison concibe a la sociedad como constituida por una pluralidad de grupos de interés compitiendo por la supremacía. Frente a estas circunstancias, la única manera de que los derechos individuales no sean vulnerados es lograr que cada grupo contrarreste a los restantes, evitando de este modo que cualquiera pueda hccerse con el completo control del aparato estatal. La competencia de los grupos de interés, y la división de las funciones del Estado en diferentes ramas de gobierno, es la mejor manera de prevenir la tiranía.

Aunque en Madison el componente pluralista de su teoría política es puesto al servicio del objetivo de evitar la tiranía, es posible encontrar en su pensamiento el germen de la teoría política pluralista: las políticas gubernamentales y las leyes surgen de la competencia de diferentes grupos de interés intentando promover sus propios objetivos, a través de la influencia que pueden ejercitar sobre el aparato gubernamental. De acuerdo con una derivación de esta idea central, en la disputa política, al igual que lo que sucede en las pujas que se dan en el seno del mercado, tenemos una competencia por recursos escasos. En política existen montos escasos de poder, influencia y dinero, y los grupos de interés compiten para alcanzar tanta influencia como les sea posible sobre los funcionarios gubernamentales encargados de diseñar las leyes y las políticas públicas.

Cada grupo de interés tiene en mente solo sus propios intereses e intenta sesgar todo el entramado institucional a su favor. Sin embargo, la pluralidad de grupos de intereses igualmente motivados y la competencia que se da entre ellos, determina que se alcance una especie de punto de equilibrio que representa el bien común, o al menos se le acerca. Al igual que lo que sucede en el mercado, donde el egoísmo individual es puesto por una mano invisible al servicio del interés colectivo, en política la competencia entre grupos de interés que intentan maximizar su poder de influencia sobre los decisores políticos conduce a una especie de punto de equilibrio colectivamente beneficioso.

Lo que cada grupo de presión busca promover son sus propios intereses, despreocupándose del interés colectivo o el bien común. El interés colectivo es alcan-

9 El corporativismo ha tenido un profundo impacto en Latinoamérica. El corporativismo estatal de ribetes autoritarios ha tenido múltiples representantes en el subcontinente (Malloy, 1977). 
zado a través del conflicto y la competencia entre grupos de interés antagónicos. El equilibrio entre diferentes facciones, y la búsqueda de ejercitar su poder de influencia sobre el aparato estatal, es lo que mejor sirve al interés de todos. La democracia no es, por lo tanto, el gobierno de la mayoría sino el gobierno de diferentes minorías en competencia. Es una especie de poliarquía que no es ni pura regla de mayoría ni regla de una minoría unificada. Es un sistema abierto, competitivo y pluralista de 'regla de minorías' (Dahl, 1956, p. 132).

De acuerdo con esta variante de pluralismo la disputa política es una por ejercitar el control -por parte de los individuos y los grupos de interés-sobre los funcionarios gubernamentales. Cada grupo de interés pugna por ejercitar su poder de influencia sobre los decisore ${ }^{10}$. Esta forma de control es diferente a la que ejerce un funcionario sobre otro - debido a la existencia de un orden jerárquico- o a la que se ejercita entre funcionarios -debido a su poder de negociación- (Dahl, 1971, 1989).

Al igual que sucede con el corporativismo, el pluralismo defiende un tipo de mediación entre los sectores productivos (básicamente los empresarios y trabajadores) junto con otros grupos sociales, y el Estado. Esta coincidencia es un punto de semejanza incuestionable entre ambas teorías políticas. Sin embargo, sus divergencias son significativas. Por un lado, el corporativismo se focaliza en la armonía que existe entre los diferentes intereses sectoriales mientras que el pluralismo se concentra en el conflicto y la competencia por recursos políticos escasos. Mientras el corporativismo enfatiza la posibilidad de cooperación entre los diferentes grupos, alcanzada a través de la intervención del Estado como agente jerárquico regulador, el pluralismo enfatiza el conflicto.

Una segunda diferencia entre el corporativismo y el pluralismo se refiere a la injerencia estatal en la organización de los grupos de presión. De acuerdo con el corporativismo el Estado puede inmiscuirse en la forma en que están estructuradas las corporaciones, confiriéndoles a cambio algunas de las atribuciones estatales. Nada semejante sucede en el pluralismo. Los grupos de presión surgen aquí libremente sin que el Estado intente controlar su número, ni conceda a algunos de ellos la representación oficial del sector en cuestión, o le confiera alguna especie de autoridad estatal

10 Existen, al menos, dos modos de entender la relación entre pluralismo y democracia. Uno, heredero de Joseph Shumpeter, considera que la democracia no se caracteriza por ser un sistema de gobierno en donde los asuntos públicos están en manos del pueblo, sino como un arreglo institucional donde "algunos individuos adquieren el poder para decidir sobre los asuntos colectivos a través de una contienda competitiva por los votos del pueblo" (Schumpeter, 1942, p. 269). El otro, es el presentado por Dahl. Aquí la Democracia sigue estando caracterizada por la soberanía popular y la igualdad política, aunque estos principios pueden ser satisfechos por un sistema poliárquico que posibilita que aquellos que ocupan cargos públicos respondan a los intereses de los ciudadanos gracias a un incesante proceso de negociación entre minorías organizadas "que operan en el contexto de una mayoría apática" (Dahl, 1958, p. 87) 
delegada. Existe en el corporativismo, en consecuencia, una tendencia a reforzar las relaciones de poder que se dan entre los grupos existentes lo que desalienta la aparición de nuevas agrupaciones. No sucede algo de esta índole en el pluralismo, donde la proliferación de grupos de presión es vista como positiva y saludable para el sistema político.

La tercera diferencia que puede señalarse entre pluralismo y corporativismo se refiere al rol del Estado. De acuerdo con el pluralismo, la tarea de implementar políticas y dictar leyes es exclusiva del Estado. Los grupos de interés intentan influir sobre el contenido de las políticas gubernamentales y la legislación, pero el dictado de ambas es un atributo propio del Estado. En el corporativismo, en cambio, las diferentes asociaciones se encuentran involucradas en la implementación de las políticas y regulaciones estatales. Es a tales efectos, como hemos señalado, que el Estado les delega algunas de sus funciones. A diferencia de lo que sucede en el pluralismo, el corporativismo ve a los grupos de interés como una herramienta del aparato estatal" ${ }^{11}$.

\subsection{Republicanismo}

Las ideas republicanas hunden sus raíces en la antigüedad clásica. El eje alrededor del cual gira toda la teoría republicana es el intento por evitar que los ciudadanos sufran un poder de interferencia incontrolado. Precisamente, la existencia de este poder es lo que vuelve aborrecible a las monarquías absolutas, donde los ciudadanos son tratados como meros súbditos sujetos a los arbitrios de quien los gobierna. Las diferentes variantes de republicanismo no son más que intentos de concebir en qué consiste esa situación deseable donde los ciudadanos no están sujetos a otros, y cuáles son los mecanismos institucionales que permitirían alcanzarla.

La aversión al poder arbitrario del monarca fue lo que originó el brote republicano en la antigua Roma. La imagen de los excesos del último rey romano (Tarquino el Soberbio) quien fue condenado al exilio debido a sus actos de tiranía, y de su hijo (Sextus) culpable de la violación de Lucretia, es el trasfondo que servirá en Roma una y otra vez para contrastar las ideas republicanas. Para protegerse de estos excesos, la república romana echó mano a una idea originada en Aristóteles: la de que tanto ciudadanos como gobernantes debe estar sujetos a la ley. A partir de entonces, el respeto por la legalidad y el cultivo en la ciudadanía de las virtudes cívicas necesarias para garantizarlo, han sido algunas de las notas distintivas de las ideas republicanas ${ }^{12}$.

11 Un estudio de casos sobre la representación de intereses en el corporativismo y el pluralismo, focalizado en Colombia, puede encontrarse en Bailey (1977).

12 Aunque el republicanismo romano se inspiró en el griego, es hoy usual distinguir al segundo como una especie de humanismo cívico que presenta a la participación política como algo intrínsecamente valioso en tanto forma parte de una visión particular de la vida buena. El republicanismo de raigambre romana, en cambio, ve a la participación política como un instrumento para evitar encontrarse sometido 
En el ideario republicano solo las leyes pueden controlar el poder del que gobierna, evitando que se vuelva arbitrario o tiránico. De esta manera, la ley es la única garante de que los ciudadanos no sean meros súbditos, esclavos de una voluntad despótica. Cualquier ciudadano que valore su propia libertad debe, en consecuencia, cultivar aquellas virtudes o rasgos de carácter que lo inclinen a obedecer las leyes de la república y a protegerla frente a potenciales amenazas. Estas amenazas, de acuerdo con el republicanismo romano, paradigmáticamente son dos: la corrupción moral y la invasión militar de una potencia extranjera. De este modo, la honestidad, cultivada a través de una vida frugal y el patriotismo, se posicionan como las virtudes cívicas por excelencia.

Las ideas republicanas resurgieron en las ciudades italianas del Renacimiento durante los siglos XV y XVI (Viroli, 2002). En el siglo XVII ocuparon un lugar central en las disputas que el parlamento inglés mantuvo con la monarquía, que finalmente condujeron a la guerra civil (Lovett, 2012). Durante el siglo XVIII las ideas republicanas tuvieron eco en Francia, especialmente gracias a las obras de Rousseau y Montesquieu. Por último, a través de las obras de pensadores ingleses y franceses, las ideas republicanas arribaron a las colonias americanas y sirvieron de sustento al andamiaje teórico de la revolución estadounidense y, posteriormente, a la construcción del entramado institucional de pesos y contrapesos configurado por la Constitución de los Estados Unidos (Sellers, 1994).

El núcleo del pensamiento republicano reside en un modo específico de concebir la libertad. Los republicanos contemporáneos, como Philip Pettit $(1997,2012)$ o Quentin Skinner (2002), ha concentrado sus esfuerzos en conferir a esta concepción de libertad contornos definidos. Para hacerlo, han contrapuesto la libertad republicana con otros modos de concebir la libertad, específicamente con la libertad positiva como autocontrol o autogobierno a la que Benjamin Constant denominaba la libertad de los antiguos y la libertad negativa como no interferencia a la que denominaba la libertad de los modernos.

La primera concepción de libertad es positiva - de acuerdo con la tipología ideada por Isaiah Berlin (2002) - porque para ser libres, los individuos necesitan participar en política o desarrollar rasgos de carácter que les permitan controlar las partes menos valiosas de su propia personalidad. La libertad de los modernos, en cambio, es un tipo de libertad negativa porque lo único que exige es la ausencia de interferencia

a la voluntad arbitraria de otro. Algunos representantes contemporáneos del humanismo cívico son Hannah Arendt (1958; 1963), J. G. A. Pocock (1975) y Paul Rahe (1992). La teoría política a la que hago referencia en el texto bajo el rótulo de republicanismo, no incluye al humanismo cívico sino solo al neorepublicanismo cuyos antecedentes se rastrean hasta Roma. 
sobre sus conductas por parte de terceros. La libertad republicana, por el contrario, posee elementos tantos de la libertad negativa como de la libertad positiva. Al igual que la libertad negativa requiere la ausencia de cierto estado de cosas, pero al igual que la libertad positiva este estado de cosas está caracterizado en términos de dominio, control o poder, en lugar de mera interferencia.

La libertad republicana exige que los individuos sean inmunes a la interferencia arbitraria o incontrolada de terceros. No basta con que los terceros se abstengan de interferir -como señala la libertad negativa de los modernos- sino que es necesario que no tengan la capacidad o el poder de hacerlo. Los individuos son libres solo cuando gozan de este estatus de inmunidad que les confieren las instituciones sociales. Cuando las instituciones ubican a los ciudadanos en esta posición de inmunidad, y no meramente cuando los terceros se abstienen de interferir, se transforman en ciudadanos libres. De acuerdo con este ideal republicano, ser libre consiste en gozar de un cierto estatus social y de un sentido de seguridad.

Al igual que sucedía en la república romana, el ciudadano libre es definido en contraposición con el esclavo. Este se encuentra bajo el dominio de su amo mientras que aquel es alguien que no se encuentra sujeto al poder incontrolado de nadie. Adicionalmente, y también al igual que en el republicanismo clásico, la única garantía de que los ciudadanos se encuentren en esta situación de inmunidad frente al poder de interferencia arbitraria de otros, es la ley. El Estado es el garante de la libertad al impedir que cualquier ciudadano pueda poseer un poder dominador sobre otros. A su vez, para que el Estado no se vuelva el mismo un poder dominador, es necesario que se encuentre bajo el control de la ciudadanía.

De acuerdo con la libertad republicana, por lo tanto, los ciudadanos son libres cuando se dan dos circunstancias. En primer lugar, existen reglas y mecanismos institucionales que impiden que cualquier ciudadano pueda tener poder de interferencia incontrolado o arbitrario sobre otro. En segundo lugar, para evitar que el aparato estatal que dicta y aplica estas reglas se vuelva el mismo un poder dominador, es necesario que este se encuentre bajo el control ciudadano. Para Pettit el control ciudadano sobre el aparato estatal debe ser individualizado, incondicionado y eficaz. El control es individualizado cuando cada ciudadano posee una capacidad de control que es igual a la que poseen los demás. El control es incondicionado cuando la influencia que cada ciudadano puede ejercitar no depende de la buena voluntad de otro. Finalmente, es eficaz cuando es tan efectivo para imprimir una dirección a las decisiones colectivas que cuando una decisión no es acorde con la dirección que un ciudadano deseaba imprimirle, este ve esta circunstancia meramente como una cuestión de mala suerte y no como la imposición de una voluntad ajena (Pettit, 2012, pp. 16-179). 
El diseño institucional que permite este tipo de control posee a grandes rasgos las siguientes características: para que la influencia tenga una dirección definida, el sistema de toma de decisiones debe ser una democracia deliberativa representativa. Debe tratarse de un gobierno mixto, donde las agencias de gobierno se controlan recíprocamente evitando que ninguna tenga un poder dominador. Finalmente, debe existir una ciudadanía contestataria cuya principal tarea es evaluar las decisiones colectivas.

\section{COLEGIATURA Y TEORÍA POLIITICA}

La manera en que se interpretan las funciones que desempeñan las instituciones sociales depende de la concepción política que se adopte como marco teórico. Esto, que es verdad como premisa general, se aplica especialmente a la manera de entender el rol que los colegios de abogados deben cumplir. La forma de concebir sus atribuciones será diferente según que uno adopte una teoría política corporativista, pluralista o republicana.

\subsection{Colegiatura y corporativismo}

En el paradigma corporativista, el modo de creación de los colegios de abogados varía según cuál sea la variante de corporativismo adoptada. En el corporativismo estatal, como hemos visto, el Estado se involucra en el surgimiento de las corporaciones que representan a los diferentes sectores sociales. En esta versión la colegiatura es una creación del Estado a través de la legislación. En el corporativismo societal, en cambio, los colegios de abogados surgen con independencia de la intervención del Estado, sin que este induzca o promueva su aparición. Que se adopte una versión u otra de corporativismo determinará el grado de independencia frente al Estado que se esté dispuesto a reconocer a los colegios. De acuerdo con el corporativismo, el Estado delega en el colegio de abogados algunas funciones de control sobre el ejercicio profesional. En general, las atribuciones que el Estado confiere al colegio se refieren a la administración de la matrícula profesional y el ejercicio del poder de disciplina sobre los matriculados. Según que el Estado aspire a tener un control mayor o menor sobre el colegio podrá reservarse el poder de confeccionar los códigos disciplinarios -por ejemplo a través de una ley- o podrá también delegar este poder legislativo en el órgano corporativo.

Como contrapartida, el Estado reconoce al colegio como el vehículo natural para canalizar y representar los intereses sectoriales de los abogados. Estos intereses sectoriales se encuentran potencialmente en conflicto con los intereses de otros sectores y es la tarea del gobierno intentar armonizarlos. En este carácter de representante de los intereses sectoriales, el colegio puede reclamar por el funcionamiento ineficiente 
del sistema judicial, por el trato inadecuado que reciben los abogados por parte de los funcionarios, por la situación de precarización en la que ejercitan su profesión, entre otras cosas. El colegio aparece como un vehículo de transmisión de las opiniones e intereses sectoriales de los abogados.

Estos intereses se consideran homogéneos hacia adentro de la corporación. Existe algo así como el interés de los abogados que se vincula con las condiciones que deben darse para que el ejercicio de la profesión sea satisfactorio. La idea es que como todos ejercen la misma profesión, las condiciones para su ejercicio eficiente son idénticas en cada uno, de lo que se sigue que todos deben tener un interés común en que estas condiciones estén garantizadas. El colegio debe vehiculizar estos intereses hacia el Estado que funciona como el principal garante de que estos intereses estén satisfechos y debe ayudar a implementar las decisiones y políticas articuladas por el Estado en relación con la profesión.

\subsection{Colegiatura y pluralismo}

Si se adopta el paradigma pluralista, el colegio también ejercita un rol mediador entre los abogados y el Estado. Sin embargo, como los intereses sectoriales son esencialmente antagónicos, el rol del colegio no es actuar como moderador de los reclamos de los abogados de manera que estos se acomoden armónicamente con los intereses de otros sectores sociales. El rol del colegio en este paradigma es promover los intereses de los abogados a través del poder de influencia sobre los decisores políticos. El colegio de abogados compite con los otros grupos de presión por los recursos políticos escasos que le permiten incidir sobre la agenda estatal. No es una herramienta para facilitar la cooperación con otros sectores sociales, sino una herramienta para poder afrontar el inevitable conflicto.

De acuerdo con la visión pluralista, el Estado no debe inmiscuirse ni en la creación ni en la organización de los colegios de abogados. Las legislaciones estatales que crean los cuerpos colegiados, establecen la colegiación obligatoria, fijan sus atribuciones y funciones, son vistas por el pluralismo como avances injustificados del Estado sobre el derecho a la libre asociación. Los colegios de abogados surgen de manera espontánea sin que el Estado confiera a algunos de ellos la representación oficial o algún tipo de autoridad estatal delegada. Si los colegios ejercen alguna forma de poder disciplinario sobre sus socios, esta no es una que le haya sido conferida por el Estado. Lo mismo se aplica al poder de dictar códigos de conducta profesional. Nada garantiza que la representación de todos los abogados esté unificada en un único cuerpo colegiado. Dado que en este paradigma los intereses por los que pugnan los diferentes grupos son esencialmente económicos, no existen razones para creer que todos los abogados, sea cual sea la manera en que ejercitan su profesión, posean intereses homogéneos. 
Es posible que las políticas estatales que promuevan los intereses económicos de los abogados corporativos, no sean las mismas que las que promueven los intereses de quienes ejercen la profesión de forma individual o en pequeños bufetes. Cada uno de estos sectores competirá por los recursos políticos escasos intentando promover sus particulares intereses.

\subsection{Colegiatura y republicanismo}

Por último, si uno adopta una teoría pluralista para interpretar el rol de los colegios de abogados, estos no pueden ser vistos como apéndices o brazos ejecutores de las políticas estatales. El colegio, como cualquier otro grupo de presión, intenta influir en las leyes y decisiones que adopta el Estado. Sin embargo, quien debe ocuparse de que estas leyes y políticas sean implementadas y ejecutadas es el propio Estado. Si se adopta una teoría republicana, finalmente, el rol del colegio de abogados adopta también contornos característicos. En este paradigma los abogados cumplen diferentes tareas que garantizan la libertad entendida como ausencia de poder de interferencia arbitraria sobre otros. En primer lugar, deben actuar como la primera barrera frente a los intentos del cliente de ejercitar un poder dominador sobre terceros. El abogado no es aquí meramente un celoso defensor de cualquier pretensión que el cliente articule, sino que debe examinar si esta es o no legítima. Proceder de otra manera sería volverse un instrumento de dominación sobre los potenciales afectados por los reclamos infundados. En segundo lugar, debe actuar como barrera para que otros ciudadanos no ejerzan un poder de dominación sobre su cliente. Debe ser el primer garante de que sus derechos, inmunidades y libertades sean respetados. En tercer lugar, debe impedir que el Estado ejerza un poder dominador sobre aquel a quien representa o defiende. Esta posibilidad de dominación es una de la que más atención y preocupación ha concitado por parte de los pensadores republicanos. Esto se debe al enorme poder de interferencia del que goza el aparato estatal. En cuarto lugar, el abogado debe realizar todas estas tareas sin volverse él mismo un instrumento de dominación sobre su cliente. Si el abogado impide que otros ciudadanos o el propio Estado ejerzan sobre su cliente un poder incontrolado, pero lo hace a través de estrategias sobre las que el cliente no ejerce ningún control -por ejemplo, porque no las ha consentido o ni siquiera las conoce- entonces la libertad republicana del cliente se encuentra amenazada.

El rol de los colegios de abogados en este paradigma, como no podía ser de otro modo, es el de garantizar la libertad como no dominación. En primer lugar, el colegio articula un control de pares sobre los abogados para evitar que estos ejerzan sobre sus clientes un poder incontrolado. Los códigos de honor, fundados en la promoción de la virtud y el castigo a través de la deshonra, cumplen aquí un rol fundamental. Este tipo de control es diferente al que se ejercita a través del derecho penal disci- 
plinario. Mientras el poder disciplinario es un poder estatal que ejercita el control de la profesión desde fuera, para utilizar una metáfora geográfica, el control a través del honor es desde dentro y es ejercido por los pares.

Tres razones han sido las que han hecho que los republicanos se encuentren inclinados a ejercitar el control sobre la profesión a través del honor. La primera, se refiere a la idea republicana de que la última garante de la libertad es una ciudadanía virtuosa, no corrompida. La segunda, tiene que ver con las peculiaridades de la relación abogado-cliente que hacen que sea difícil controlarla de manera externa. La exigencia de que la relación esté protegida por el deber de secreto o sigilo, por ejemplo, determina que las posibilidades de control por parte de los pares o por parte del propio abogado sean mucho mayores. La tercera, ha sido la desconfianza republicana a la injerencia por parte del Estado en la regulación de una profesión que tiene como uno de sus objetivos proteger a los ciudadanos del poder dominador estatal. Si se permite que el Estado regule el ejercicio profesional a través de su poder disciplinario, es posible que este utilice dicho poder para hostigar a los abogados que están intentando proteger a los ciudadanos de los intentos estatales de ejercitar un poder dominador ilegítimo. Ante este riesgo, los republicanos han optado por regular la profesión a través del control de pares basado en la virtud y el honor.

Esta última razón se vincula con la segunda función que cumplen los colegios de abogados en el paradigma republicano. Dado que los abogados tienen entre sus tareas la de ser la primera barrera que se interpone entre los ciudadanos y el poder arbitrario del Estado, la situación de vulnerabilidad en la que se encuentran es alta. Si el abogado tiene que actuar como una especie de freno o contrapeso al poder dominador del Estado, las perspectivas no parecen demasiado prometedoras. Frente al colosal poder de interferencia estatal se erige un único profesional como primera barrera. La colegiatura viene a compensar, aunque sea parcialmente, esta desventaja. El colegio de abogados funciona como un reaseguro de que el Estado no perseguirá u hostigará a los profesionales porque detrás de cada abogado, por así decirlo, ahora están todos.

Por último, los colegios de abogados deben actuar como órganos que visibilizan y denuncian las amenazas a la libertad como no-dominación que pesan sobre los ciudadanos. Esto porque en el paradigma republicano los abogados, y por ende el colegio que los agrupa, tienen en mente la protección de la libertad republicana de la ciudadanía. El colegio no es aquí un órgano que simplemente vehiculiza los reclamos sectoriales hacia el gobierno, sino uno que actúa él mismo como freno al poder dominador estatal, garante de la libertad individual de todos los que constituyen la comunidad política. 


\section{COLEGIATURA Y VIOLENCIA INSTITUCIONAL}

Con las diferentes justificaciones de la colegiación profesional a mano, es posible tener una visión más clara del diferente rol que tendrán los colegios de abogados frente a la violencia institucional según que se adopte alguna de ellas. Si se adopta una visión corporativista las perspectivas de que el colegio de abogados cumpla un rol activo enfrentando y poniendo freno a la violencia ilegítima ejercida por parte de funcionarios estatales es reducida. Las razones para que esto sea así son dos. La primera, tiene que ver con la idea corporativista de que los intereses de los diferentes sectores sociales son armonizados por la actividad del Estado. Si se adopta una visión armónica de la sociedad, y se concibe al Estado como el principal catalizador de la misma, existen pocas posibilidades de percibir si quiera algún caso de violencia estatal ilegítima. El marco teórico utilizado aquí, y el rol atribuido al Estado, vuelve dificultoso identificar algún tipo de coacción estatal que no pueda ser justificada en aras de la armonía. La segunda, se vincula con el carácter cuasiestatal que poseen los colegios en el paradigma corporativista. La injerencia del Estado en el surgimiento y organización de los colegios de abogados, el dictado de los códigos disciplinarios que estos están encargados de aplicar, la obligación de los colegios de contribuir a aplicar las leyes y políticas estatales, hace que estos no sean una herramienta adecuada para enfrentar los comportamientos gubernamentales que puedan configurar casos de violencia institucional.

Si se adopta el paradigma pluralista, el potencial de que los colegios se vuelvan herramientas que protejan a la ciudadanía de la violencia ilegítima ejercida por parte del Estado es mayor. Esto porque, a diferencia de lo que sucede en el paradigma corporativista, el colegio no es visto como el brazo ejecutor del Estado. Sin embargo, este potencial es limitado dado el modo en que el pluralismo concibe a los grupos de presión. Cada grupo de presión está solo preocupado por la consecución de sus intereses sectoriales. Dentro del enfoque pluralista, el colegio, o las diferentes asociaciones de abogados, estarán preocupadas solo por promover los intereses de sus asociados, desentendiéndose de los riesgos que pueda enfrentar la ciudadanía, incluidos los de ser víctima de la violencia institucional.

En el paradigma pluralista el colegio solo está preocupado por el interés sectorial de aquellos profesionales a los que agrupa. Cualquier interés que manifieste por la protección de los derechos de los ciudadanos amenazados por la violencia institucional, solo será una consecuencia de la búsqueda de promocionar los intereses de los abogados o un instrumento para alcanzarlo. La preocupación que el colegio puede manifestar por el modo en que funciona el sistema de justicia, por ejemplo, no tendrá por objetivo garantizar la protección de los intereses ciudadanos sino permitir que sus asociados puedan desempeñar de una manera eficiente y lucrativa su profesión. 
En este sentido, no existe ninguna diferencia cualitativa entre el rol del colegio y el de cualquier otro lob6y empresarial.

Por último, si se adopta el paradigma republicano, el rol del colegio frente a la violencia institucional se vuelve fundamental. Aquí, al igual que sucede en el pluralismo, el colegio no es visto como una institución auxiliar del Estado. Adicionalmente, y a semejanza de lo que sucede en el corporativismo, el colegio concibe sus funciones como orientadas al interés público. Sin embargo, este interés no viene definido por el Estado en tanto armonizador de los diferentes intereses sectoriales, sino por una idea de libertad como no-dominación que permite evaluar, y en su caso enfrentar, las diferentes políticas estatales.

En este paradigma republicano, las funciones del colegio frente a la violencia institucional son dos. En primer lugar, actúa como escudo protector de aquellos abogados involucrados en causas donde es el propio Estado el que se ha erigido en una amenaza para los ciudadanos, a través de la violencia ejercitada de manera ilegítima por sus funcionarios. En segundo lugar, él mismo debe actuar como barrera de contención de la violencia ejercitada desde el Estado. Esto en tanto una de las funciones del colegio es proteger la libertad como no-dominación de la ciudadanía -y no solo los intereses sectoriales de sus asociados- y una de las amenazas más graves a esta libertad es la coacción ejercitada de manera incontrolada, esto es ilegítima, por parte del Estado.

\section{CONCLUSIONES}

Ha sido mostrado que la manera de entender las funciones de los colegios profesionales de abogados depende de la teoría política que se adopte para justificar su existencia. Específicamente, en lo que respecta a la violencia ejercitada desde el Estado, estos pueden actuar como frenos que la detienen o controlan solo si interpretan su rol en clave republicana.

Esta conclusión puede servir de insumo para trabajos de investigación ulteriores. Por caso, puede servir para generar hipótesis explicativas del rol pasivo que algunas asociaciones de abogados tuvieron durante las dictaduras militares que asolaron Latinoamérica durante en la década de 1970 y la violencia institucional inusitada que descargaron sobre la ciudadanía y sobre aquellos abogados que osaban enfrentárseles. Quizás este comportamiento puede ser explicado, en parte, en el marco de una matriz corporativista que veía al colegio como una especie de auxiliar del Estado. Que los colegios adoptasen esta forma de ver su propia función tal vez pueda rastrearse a causas que hunden sus raíces en la influencia que el corporativismo católico, primero, y el fascismo, después, tuvieron en Latinoamérica ${ }^{13}$.

13 El caso argentino es en este sentido paradigmático. La violencia institucional se descargó de manera especialmente violenta sobre los abogados que osaron enfrentar a la dictadura militar del denominado 
Puede elaborarse una hipótesis explicativa semejante, que necesitará de corroboración empírica, del rol igualmente pasivo que desempeñaron frente a la violencia institucional desatada por los gobiernos de corte neoliberal que en la década de 1990 cobraron fuerza en el subcontinente ${ }^{14}$. La violencia institucional desatada entonces no fue algo contingente, esporádico o accidental. Tal como señala Ian Bruff la agenda neoliberal "desde el comienzo ha estado menos interesada en conferir un libre reinado a los mercados que en manejar y realizar ingeniería sobre los mercados que desea ver que aparezcan. Más aún, la coerción Estado-céntrica aislada de presiones democráticas es central para la creación y mantenimiento de esto orden político-económico, defendiéndolo en contra de los impulsos por mayor igualdad y democratización" (Bruff, 2016, p. 107).

Según esta hipótesis, lo que explicaría que los colegios no hayan alzado su voz contra los atropellos que el Estado cometía con la excusa de garantizar la seguridad amenazada por las protestas sociales, tal vez era que dentro de una matriz neoliberal el modo más natural de concebir la función de los colegios es aquella que propone el paradigma pluralista. Los colegios no son más que grupos de presión que intentan promover los intereses económicos del sector que representan.

Si estas hipótesis explicativas finalmente son corroboradas a través de una investigación empírica, tendremos razones adicionales de carácter empírico para dar sustento a la conclusión normativa obtenida en este trabajo que muestra que los colegios vislumbran como una de sus funciones servir de freno a la violencia institucional si adoptan para justificarse una teoría política republicana.

\section{REFERENCIAS}

Arendt, H. (1958). The Human Condition. Chicago: University of Chicago Press.

Arendt, H. (1963). On Revolution. Nueva York: Viking Press.

Auyero, J. (2000). The hyper-shantytown: Neo-liberal violence(s) in the Argentine slum. Ethnography, $1(1), 93-116$.

proceso de reorganización nacional. Algunos de los casos más resonantes sucedieron en la que luego se conocería como la noche de las corbatas, donde fueron secuestrados y asesinados abogados laboralistas (Celesia y Waisberg, 2016). Sobre el papel pasivo de los colegios de abogados puede verse el libro de Esteban Ortiz (2015) El derecho víctima del terrorismo de Estado 1975-1980.

14 Argentina, nuevamente, es aquí un ejemplo paradigmático. Las políticas neoliberales implementadas durante los años noventa incidieron en el incremento de la violencia interpersonal, la represión estatal y la violencia estructural (Auyero, 2000). Los estudios que documentan la relación entre neoliberalismo y violencia en diferentes contextos nacionales son numerosos (Borras y Ross, 2007; Chatterjee, 2009; Coleman, 2007; Collier, 2008; Goldstein, 2005; Marchand, 2004). 
Bailey, J. (1977). Pluralist and corporatist dimension of interest representation in Colombia. En J. M. Malloy (Ed.), Authoritarianism and Corporatism in Latin America (pp. 259-302). Pittsburgh: University of Pittsburgh Press.

Barak, G. (2003). Violence and nonviolence: pathways to understanding. Thousand Oaks: Sage Publications.

Berlin, I. (2002). Two Concepts of Liberty. En H. Hardy (Ed.), Liberty (pp. 166-217). Oxford: Oxford University Press.

Bisig, E. (2014). Del disciplinamiento a la exclusión social: circulación de los jóvenes en la ciudad. En E. Bisig (Ed.), Jóvenes y seguridad: control social y estrategias punitivas de exclusión Código de Faltas Provincia de Córdoba (pp. 117-134). Córdoba: Centro de Investigaciones Jurídicas y Sociales.

Borras, S. y Ross, E. (2007). Land Rights, Conflict, and Violence Amid Neo-Liberal Globalization. Peace Review: A Journal of Social Justice, 19, 1-4.

Bruff, I. (2016). Neoliberalism and authoritarianism. En S. Springer, K. Birch y J. MacLeavy (Eds.), The Handbook of Neoliberalism (pp. 107-117). Nueva York: Routledge.

Celesia, F. y Waisberg, P. (2016). La noche de las corbatas: cuando la dictadura silenció a los abogados de los trabajadores. Buenos Aires: Aguilar.

Chatterjee, I. (2009). Social conflict and the neoliberal city: a case of Hindu-Muslim violence in India. Transactions of the Institute of British Geographers, 34(2), 143-160.

Chubb, J. (1983). Interest groups and the bureaucracy: the politics of energy. Stanford: Stanford University Press.

Coffey, J. (2003). Léon Harmel: Entrepreneur as Catholic Social Reformer. Notre Dame: University of Notre Dame Press.

Coleman, L. (2007). The Gendered Violence of Development: Imaginative Geographies of Exclusion in the Imposition of Neo-Liberal Capitalism. The British Journal of Politics and International Relations, 9, 204-219.

Collier, C. (2008). Neoliberalism and Violence against Women: Can Retrenchment Convergence Explain the Path of Provincial Anti-Violence Policy, 1985-2005? Canadian Journal of Political Science, 41, 19-42.

Cox, A. y O'Sullivan, N. (1988). The Corporate State: Corporatism and the State Tradition in Western Europe. Aldershot: Edward Elgar.

Dahl, R. (1956). A Preface to Democratic Theory. Chicago: University of Chicago Press.

Dahl, R. (1958). Hierarchy, Democracy and Bargaining in Politics and Economics. En H. Eulau, S. Eldersveld y M. Janowitz (Eds.), Political Behavior. A Reader in Theory and Research. Glencoe: The Free Press.

Dahl, R. (1971). Polyarchy: Participation and Opposition. New Haven: Yale University Press. 
Dahl, R. (1989). Democracy and Its Critics. New Haven: Yale University Press.

Espoz, M. B. (2009). La ciudad y las ciudades-barrio: tensión y conflicto a partir de una lectura de la producción mediática de miedos en el marco de espacios urbanos socio-segregados. Revista Latinoamericana de Estudios sobre Cuerpos, Emociones y Sociedad, (1), 78-87

Goldstein, D. (2005). Flexible Justice: Neoliberal Violence and 'Self-Help' Security in Bolivia. Critique of Anthropology, 25, 389-411.

Hanson, E. (1987). The Catholic Church in World Politics. Princeton: Princeton University Press.

Lovett, F. (2012). Harrington's Empire of Law. Political Studies, 60, 59-75.

Malloy, J. M. (1977). Authoritarianism and corporatism in Latin America: the modal pattern. En J. M. Malloy (Ed.), Authoritarianism and Corporatism in Latin America (pp. 3-22). Pittsburgh: University of Pittsburgh Press.

Marchand, M. (2004). Neo-liberal Disciplining, Violence and Transnational Organizing: The struggle for women's rights in Ciudad Juárez. Development, 47, 88-93.

Ortiz, E. R. (2015). El derecho víctima del terrorismo de Estado 1975-1980. Río Cuarto: UniRío.

Pettit, P. (1997). Republicanism: A Theory of Freedom and Government. Oxford: Oxford University Press.

Pettit, P. (2012). On The People's Terms: A Republican Theory and Model of Democracy. Cambridge: Cambridge University Press.

Pocock, J. G. A. (1975). The Machiavellian Moment: Florentine Political Thought and the Atlantic Republican Tradition. Princeton: Princeton University Press.

Rahe, P. (1992). Republics Ancient and Modern: Classical Republicanism and the American Revolution. Chapel Hill: University of North Carolina Press.

Schmitter, P. y Lehmbruch, G. (Eds.). (1985). Patterns of Corporatist Policy Making. Londres: Macmillan.

Schumpeter, J. (1942). Capitalism, Socialism and Democracy. Nueva York: Harper and Row.

Sellers, S. (1994). American Republicanism: Roman Ideology in the United States Constitution. Nueva York: New York University Press.

Skinner, Q. (2002). A Third Concept of Liberty. Proceedings of the British Academy, 117, 237-268.

Viroli, M. (2002). Republicanism. Nueva York: Hill and Wang. 